\title{
REVIEW ARTICLE OPEN \\ Neural circuits and nicotinic acetylcholine receptors mediate the cholinergic regulation of midbrain dopaminergic neurons and nicotine dependence
}

\author{
Cheng Xiao ${ }^{1,2}$, Chun-yi Zhou ${ }^{1,2}$, Jin-hong Jiang ${ }^{1,2}$ and Cui Yin ${ }^{1,2}$
}

\begin{abstract}
Midbrain dopaminergic (DA) neurons are governed by an endogenous cholinergic system, originated in the mesopontine nuclei. Nicotine hijacks nicotinic acetylcholine receptors ( $\mathrm{nAChRs)}$ and interferes with physiological function of the cholinergic system. In this review, we describe the anatomical organization of the cholinergic system and the key $n A C h R$ subtypes mediating cholinergic regulation of DA transmission and nicotine reward and dependence, in an effort to identify potential targets for smoking intervention. Cholinergic modulation of midbrain DA systems relies on topographic organization of mesopontine cholinergic projections, and activation of $n A C h R s$ in midbrain DA neurons. Previous studies have revealed that $a 4, a 6$, and $\beta 2$ subunitcontaining $\mathrm{nAChRs}$ expressed in midbrain DA neurons and their terminals in the striatum regulate firings of midbrain DA neurons and activity-dependent dopamine release in the striatum. These nAChRs undergo modification upon chronic nicotine exposure. Clinical investigation has demonstrated that partial agonists of these receptors elevate the success rate of smoking cessation relative to placebo. However, further investigations are required to refine the drug targets to mitigate unpleasant side-effects.
\end{abstract}

Keywords: midbrain DA neurons; mesopontine; cholinergic neurons; nicotinic acetylcholine receptors; neural circuits; nicotine reward and dependence; smoking intervention

Acta Pharmacologica Sinica (2020) 41:1-9; https://doi.org/10.1038/s41401-019-0299-4

\section{INTRODUCTION}

Cigarette smoking causes the most preventable diseases worldwide [1]. Nicotine is a bioactive compound in cigarettes that exerts rewarding effects by activating nicotinic acetylcholine receptors ( $\mathrm{nAChRs}$ ) in the central nervous system. Repetitive nicotine intake modifies plasticity in the central nervous system, leading to nicotine dependence [2]. Among the brain regions responsive to nicotine, the midbrain contains dopaminergic (DA) neurons, which have been implicated in a wide range of physiological functions, including reward processing, reinforcement learning, aversion avoidance, and motivation [3, 4]. Therefore, the midbrain is unique in that it is the target of nicotine for the development and maintenance of nicotine dependence.

Midbrain neurons are governed by the endogenous cholinergic system, originating in the mesopontine nuclei [5-8]. Nicotine hijacks $n A C h R s$ and interferes with the physiological function of endogenous $\mathrm{ACh}$, and thus identifying and characterizing the key ACh receptors that mediate the cholinergic regulation of DA transmission may advance our understanding of the circuit mechanisms underlying nicotine dependence.

In this article, we review the topographic organization of the cholinergic system that governs midbrain DA neurons, the composition of $\mathrm{ACh}$ receptors that mediate the cholinergic modulation of midbrain neurons, the subtypes of nAChRs modified by chronic exposure to nicotine, and the subtypes of $\mathrm{nAChRs}$ implicated in nicotine dependence.

\section{TOPOGRAPHIC ORGANIZATION OF THE CHOLINERGIC SYSTEM FOR THE REGULATION OF MIDBRAIN DA NEURONS}

Midbrain DA neurons are distributed in the ventral tegmental area (VTA) and the substantia nigra pars compacta (SNc), and they receive dense cholinergic innervation from mesopontine cholinergic nuclei, including the pedunculopontine tegmental nucleus (PPN) and the laterodorsal tegmental nucleus (LDT) [5-8]. Previous studies have revealed that the mesopontine cholinergic innervation of midbrain DA neurons is topographically organized and forms anatomical substrates for the independent regulation of different behaviors by the mesopontine cholinergic system $[6,8,9]$.

\section{Anatomy of the PPN and LDT}

The PPN is located in the pons of the upper brainstem, and its border can be demarcated by staining with an antibody against choline acetyltransferase, a marker protein of cholinergic neurons [6]. Its rostral-ventral end begins just below the red nucleus and posterior to the $\mathrm{SN}$, and its dorsal-posterior edge is in front of the anterior parabrachial nucleus. The PPN is located medial to the medial lemniscus and the superior cerebellar peduncle, lateral to

\footnotetext{
${ }^{1}$ School of Anesthesiology, Xuzhou Medical University, Xuzhou 221004, , China and ${ }^{2}$ Jiangsu Province Key Laboratory in Anesthesiology, Xuzhou Medical University, Xuzhou 221004, , China

Correspondence: Cheng Xiao (xchengxj@xzhmu.edu.cn) or Chun-yi Zhou (chunyi@xzhmu.edu.cn)
}

Received: 27 May 2019 Accepted: 6 August 2019

Published online: 25 September 2019 

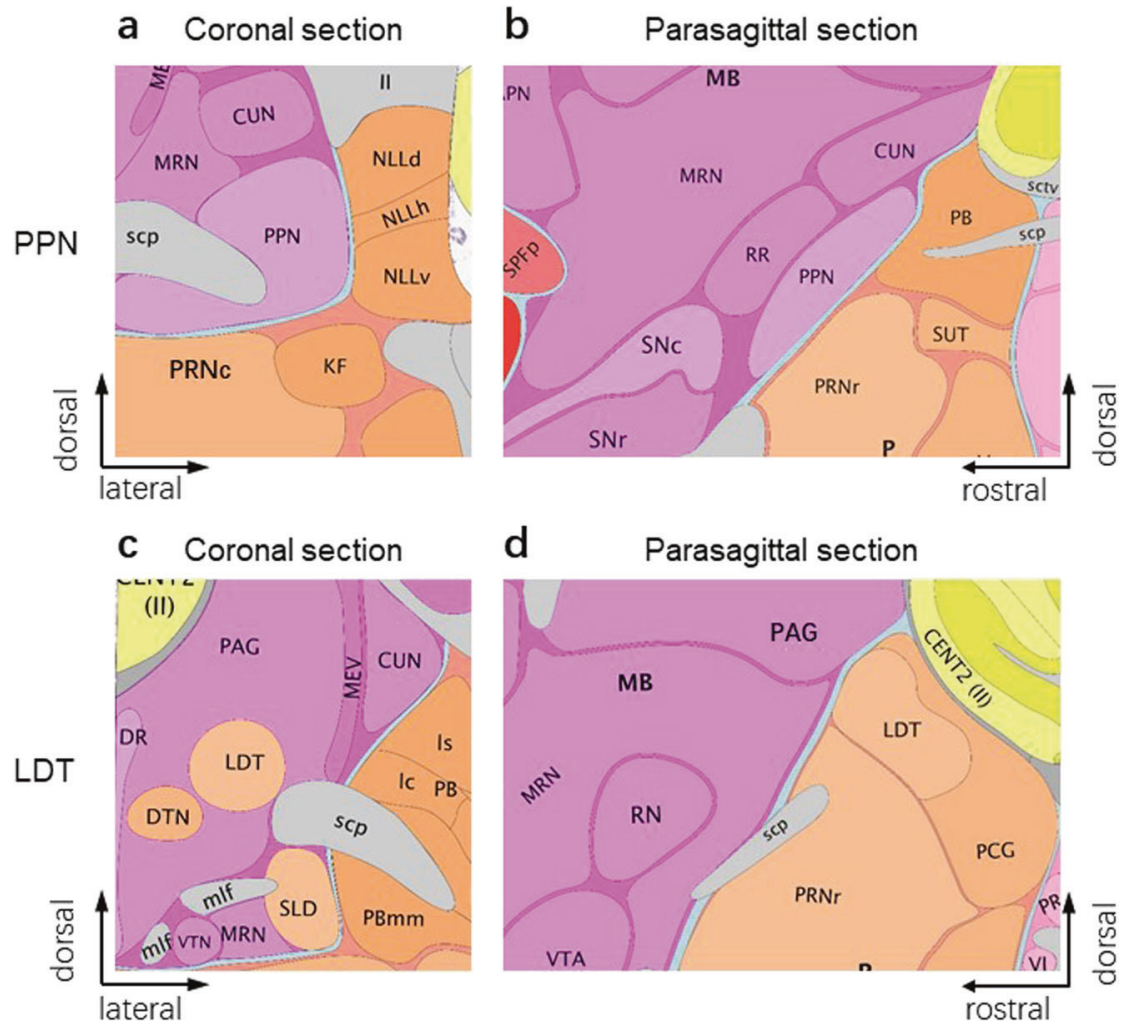

Fig. 1 Anatomy of the pedunculopontine nucleus (PPN) and the lateral dorsal tegmental nucleus (LDT). a Coronal section containing the pedunculopontine nucleus (PPN). b Parasagittal section containing the PPN. c Coronal section containing the LDT. d Parasagittal section containing the LDT. CUN: cuneiform nucleus. DR: dorsal raphe. DTN: dorsal tegmental nucleus. mlf: medial longitudinal fascicle. MRN: midbrain reticular nucleus. PAG: periaqueductal gray. PB: parabrachial nucleus (Ic: lateral part, central lateral; Is: lateral part, superior lateral). PCG: pontine central gray. PRNc: pontine reticular nucleus, caudal. PRNr: pontine reticular nucleus, rostral. RN: raphe nucleus. RR: retrorubral area. Scp: superior cerebellar peduncle. SLD: sublaterodorsal nucleus. SNc: substantia nigra pars compacta. SNr: substantia nigra pars reticulata. VTA: ventral tegmental area. Image credit: Allen Adult Mouse Brain Reference Atlas

the brachium conjunctivum, ventral to the retrorubral area of the midbrain reticular nucleus and the cuneiform nucleus, and dorsal to the pontine reticular nucleus and the parabrachial nucleus (Fig. 1a, b, atlas.brain-map.org). Neurons in the PPN are heterologous in density, size, and neurochemistry. The PPN is divided into the rostral half, the pars dissipata (PPNd), and the caudal half, the pars compacta (PPNc). The PPNd and PPNc mainly consist of small GABAergic neurons and large cholinergic and glutamatergic neurons, respectively [10]. It is noteworthy that the cholinergic neurons also contain nitric oxide synthase, substance $P$ and atrial natriuretic peptide [10]. Similar to the cuneiform nucleus, the PPN is a major component of the mesencephalic locomotor region $[11,12]$. The electrical stimulation of this region promotes locomotion [11]. A recent elegant study utilizing a cell-specific optogenetic technique revealed that PPN glutamatergic and GABAergic neurons respecitvely facilitate and inhibit movement in mice [12].

The LDT is medial-posterior to the PPN. It is embedded in the pontine central gray and lies between the caudal part of the dorsal raphe and the parabrachial nucleus and ventral to the caudal part of the ventral periaqueductal gray (Fig. 1c, d, atlas.brain-map.org). Similar to the PPN, the LDT contains cholinergic, glutamatergic and GABAergic neurons $[6,7]$.

Cholinergic modulation of the midbrain

PPN and LDT cholinergic neurons release acetylcholine (ACh) into the midbrain and regulate neuronal activity via activating nicotinic and muscarinic ACh receptors ( $n A C h R s$ and mAChRs) in these neurons. nAChRs are ligand-gated cation channels, and each individual receptor is composed of five subunits. Each subunit has four transmembrane domains, of which the second transmembrane domain faces the pore of the channel. nAChR subunits in the central nervous system include a2-7 and $\beta 2-4[13,14]$. These subunits form either homomeric pentamers (i.e., $\alpha 7$ ) or heteromeric pentamers (which include two or three a-subunits and three or two $\beta$-subunits). mAChRs belong to a family of seventransmembrane G-protein coupled receptors that include five members (M1-M5) [15]. M1, M3, and M5 receptors are coupled with Gq. M2 and M4 receptors are coupled with Gi and inhibit adenosine monophosphate cyclase, potassium channels, and calcium channels, etc.

PPN and LDT cholinergic neurons regulate SNc and VTA neurons by different patterns

The cholinergic neurons in the PPN and LDT regulate both SNC and VTA neurons through activating acetylcholine receptors in these neurons [8]. Combining optogenetic and brain slice patchclamp techniques, Xiao et al. [8] demonstrated that 5-10 s of optogenetic stimulation of cholinergic projections from the PPN and LDT evokes inward currents and increases the firing rates in both SNc and VTA neurons. The effects can be blocked by a nAChR antagonist but not by antagonists of mAChRs and GABA receptors. Interestingly, in some midbrain neurons, blocking AMPA and NMDA receptors significantly attenuates cholinergic responses. These data suggest that the cholinergic responses are mediated by nAChRs in the midbrain neurons and in the glutamatergic terminals that synapse onto these midbrain neurons. This finding is consistent with that of a previous electrophysiological study in which the authors applied electrical stimulation to the PPN and found that blocking nAChRs 
attenuated glutamatergic responses in the VTA [16] and the SNC [17]. Using in vivo single-unit recordings from anesthetized rats, Dautan et al. [5] applied optogenetic stimulation to cholinergic neurons in the PPN and the LDT and observed the excitation of VTA DA neurons, which are regulated by AChRs (the effect is blocked by locally applied atropine and mecamylamine). Although some PPN cholinergic neurons are glutamatergic or GABAergic neurons [18] and corelease ACh with glutamate or GABA, using optogenetic techniques to stimulate PPN cholinergic terminals in the midbrain does not evoke the release of glutamate or GABA from the terminals $[5,8]$, indicating that PPN cholinergic neurons that contain ACh and glutamate or GABA do not project to the midbrain. Viral vector-assisted retrograde neuronal tracing shows that cholinergic neurons account for most PPN neurons that project to the ventral SNc [8] but only a minority of LDT neurons that project to the VTA [8]. Instead, most VTA-projecting LDT neurons are glutamatergic [19]. Therefore, PPN and LDT cholinergic neurons may selectively innervate certain regions in the midbrain.

Topographic organization of PPN and LDT cholinergic projections to the SNc and VTA

PPN and LDT cholinergic neuron projections to the SNc and VTA display particular patterns of topographic organization [6]. In the lateral-to-medial dimension, midbrain DA neurons are distributed in the lateral SNc, medial SNc and VTA, which respectively receive cholinergic afferents from the PPNd, PPNc, and LDT [6]. In general, PPNd neurons mainly project to the lateral SNc; PPNc neurons project to both the SNc and VTA, while LDT neurons mainly project to the VTA (Fig. 2). The distribution of cholinergic neurons that project to the substantia nigra (SN) shows a gradient along the anterior-posterior axis of the PPN. SN-projecting cholinergic neurons account for $\sim 35 \%, 25 \%$, and $15 \%$ of neurons in the rostral, middle, and caudal thirds of the PPN [20], respectively, but are rarely found in the LDT [21]. VTA-projecting neurons are distributed throughout the PPN and LDT with higher densities in the PPNC and LDT, in which cholinergic neurons are densely distributed [21]. This topographic feature of mesopontine cholinergic afferents to the midbrain is the anatomical basis for the differential regulation of locomotion and reward behaviors. PPNc cholinergic neurons that project to the SNc and VTA regulate locomotion and reward [8], respectively. LDT cholinergic neurons regulate both SNc and VTA neurons but regulate behaviors in a

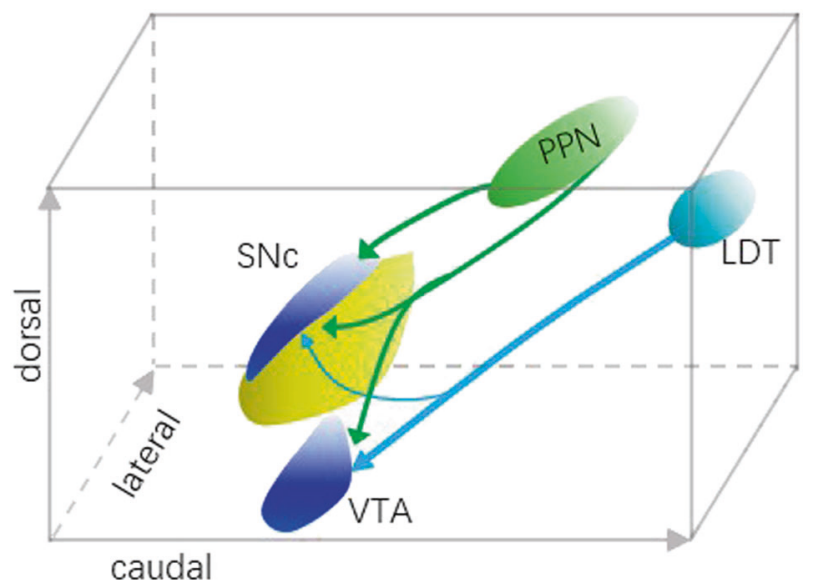

Fig. 2 Topographic organization of the midbrain cholinergic system. The rostral and caudal parts of the PPN project to the lateral SNc and medial SNc and lateral VTA, respectively. The LDT projects preferentially to the VTA rather than the medial SNc. Blue represents DA neurons, while cyan and green represent cholinergic neurons in the LDT and PPN, respectively. In each individual nucleus, the color gradually becomes lighter from the medial to the lateral portion pattern different from that by which PPN cholinergic neurons do [8]: stimulating LDT cholinergic terminals in the VTA elicits rewardrelated behaviors, while stimulating those in the SNc does not promote locomotion.

PPN cholinergic projections differentially regulate the lateral and medial SNC

The dorsal SNc is divided into medial and lateral portions by the oculomotor nerve. DA neurons in these two portions are distinct in electrophysiological characteristics, such as membrane potential, the size of hyperpolarization-activated cyclic nucleotide-gated cation channels, and spontaneous firing rate [9]. This study revealed that PPN cholinergic neurons form disparate types of connections with medial and lateral SNc DA neurons. In the lateral $\mathrm{SNc}$, PPN cholinergic terminals release $\mathrm{ACh}$ and then activate $\mathrm{nAChRs}$ on DA neurons and glutamatergic terminals, resulting in excitation of DA neurons, similar to another study [8]. In the medial SNc, PPN cholinergic terminals release ACh (activating $n A C h R s$ on DA neurons and GABAergic terminals) or corelease GABA (activating $n A C h R s$ and $G_{A B A}$ receptors on DA neurons), leading to inhibition of DA neurons. At the behavioral level, the stimulation of PPN cholinergic terminals in the lateral and medial SNc enhances and inhibits locomotion, respectively. This is the first study to unambiguously demonstrate that some mesopontine cholinergic neurons corelease $\mathrm{ACh}$ and GABA and are critically implicated in the regulation of downstream neurons and related behaviors.

Estakhr et al. [9] demonstrated the corelease of ACh and GABA from PPN cholinergic terminals in the SNc of ChAT-Cre mice, which is different from what was shown by another study using ChAT-Cre rats [8]. In that study, AAV5 was used to limit the transfection area, and only $50 \%-60 \%$ of cholinergic neurons in the PPNc were successfully transduced with channelrhodopsin [8]. It has been shown that the PPNc contains fewer GABAergic neurons than the PPNd [10]. Therefore, the different results between these two similar optogenetic studies may have resulted from anatomical variation between species or differences in the transduction efficiency of viral vectors or the locations of the optogenetically labeled neurons.

Note that the properties of PPN-LDT cholinergic projections to the midbrain differ from those of medial habenular ( $\mathrm{MHb}$ ) cholinergic projections to the interpedunculopontine nucleus (IPN). Habenular cholinergic neurons corelease ACh and glutamate and stimulate IPN neurons by activating both glutamate receptors and $\mathrm{nAChRs}$ [22]. This supports previous histological studies showing that a large proportion of $\mathrm{MHb}$ neurons produce $\mathrm{ACh}$ and glutamate [23].

\section{ACETYLCHOLINE RECEPTOR SUBTYPES MEDIATE THE CHOLINERGIC MODULATION OF THE MIDBRAIN}

The stimulation of cholinergic afferents results in multiphasic alterations in neuronal firing in vivo [24-27]. Stimulating PPN neurons with kainate increases the firing rate of DA neurons in the ipsilateral substantia nigra by activating nAChRs [27]. Foster and Blaha applied $35 \mathrm{~Hz}$ electrical stimulation to the LDT and PPN every other second for $1 \mathrm{~min}$ and recorded triphasic alterations (the first increase, second decrease, and third sustained elevation) in dopamine levels in the nucleus accumbens (NAcc) and the caudate putamen $(\mathrm{CPu})$, indicating that stimulating these cholinergic nuclei modulates midbrain DA neurons $[25,26]$. Pharmacological evidence has revealed that these responses are, respectively, mediated by nAChRs in the VTA/SN, mAChRs in the LDT/PPN, and mAChRs in the VTA/SN. Therefore, nAChRs and mAChRs in the VTA/SN mediate the fast and slow excitation of VTA/SN neurons, respectively, following stimulation of the PPN and LDT. It is noteworthy that PPN and LDT cholinergic projections not only regulate midbrain DA neurons but are also modulated by nicotine. 
In the PPN and LDT, nicotine activates nAChRs in non-cholinergic neurons and indirectly modulates cholinergic neurons [28]. This circuitry contributes to nicotine reinforcement learning because lesions of PPN cholinergic neurons or the inhibition of nAChRs in the PPN reduces nicotine self-administration in rats [29].

Subtypes of $\mathrm{nAChRs}$ in midbrain neurons

Accumulating evidence has demonstrated that M5-type mAChRs in midbrain DA neurons mediate the sustained increase of dopamine release in the striatum following the electrical stimulation of the PPN [30-32]. In midbrain DA neurons, the subtypes of nAChRs are more complicated than those of mAChRs. Smoking-relevant concentrations of nicotine activate nAChRs, increase the firing rate of DA neurons in the VTA [33-35] and SNC [36-38], and evoke prolonged irregular firing in these neurons [38]. The excitation of VTA DA neurons is much stronger than that of SNc DA neurons $[36,38]$, suggesting that $n A C h R$ subtypes in VTA and SNc DA neurons and the neural circuitry in the VTA and SNc may be different.

Expression of $n A C h R$ subtypes in midbrain neurons. Using doublelabeling in situ hybridization, Azam et al. [39] identified nAChR subunit messenger RNAs (mRNAs) expressed in SN and VTA DA neurons. They found that these DA neurons contain a2-7 and $\beta 2-4$ subunits. Specifically, almost all SNc and VTA DA neurons contain $\alpha 2, a 4, \alpha 5, a 6, \beta 2$, and $\beta 3$ nAChR mRNAs; some also contain $\alpha 3$ and a7 mRNAs and few neurons contain $\beta 4$ mRNA. In the SN, $\alpha 4, \beta 2$, $a 7$, and $\beta 4$ mRNAs are also detected in non-DA neurons. The results are consistent with those of another study showing that 6OHDA-induced lesions in SNc DA neurons eliminate $a 3, a 5, a 6$, and $\beta 4$ subunit mRNAs but only reduce the levels of $a 4, \alpha 7, \beta 2$, and $\beta 3$ subunit mRNAs in the SN. Thus, $a 3, a 5, a 6$, and $\beta 4$ subunits are selectively expressed in SNc DA neurons, while $\alpha 4, \alpha 7, \beta 2$, and $\beta 3$ subunits consist of major nAChR subtypes in both DA and nonDA neurons [40]. The selective expression of $a 3, a 5, a 6$, and $\beta 3$ subunits in midbrain DA neurons has also been supported by many other studies [41-45].

Functional $n A C h R s$ in midbrain DA neurons. To understand how nAChR subunits integrate and form functional receptors to regulate midbrain DA neurons, many studies have utilized ex vivo patch-clamp recordings to define $A C h$ responses in midbrain DA neurons with drugs selective for $\mathrm{nAChR}$ subtypes and with mouse lines having genetically modified $n A C h R$ subunits. These studies have delineated four types of $A C h$ responses in midbrain DA neurons [46-49]. The first type is sensitive to dihydro$\beta$-erythroidine, an antagonist of $n A C h R s$ containing a $4 \beta 2$ subunits. The second type is mediated by a7-containing nAChRs and blocked by methyllycaconitine or a-bungarotoxin. The third type is the combination of the first and second types. The fourth type is sensitive to low concentrations of mecamylamine, which preferentially blocks a $3 \beta 4$-containing $n A C h R s$.

a4 32 - and a7-containing nAChRs may differ between VTA and SNc DA neurons. Electrophysiological analysis of nAChR currents, autoradiography of $\left[{ }^{125} \mathrm{I}\right]$-a-bungarotoxin binding (specific for a7 $\mathrm{nAChRs)}$, and in situ hybridization have revealed that the major components for ACh-evoked responses in midbrain DA neurons are mediated by $a 4 \beta 2$ nAChRs, and VTA DA neurons contain higher levels of a7 nAChRs than SNc DA neurons $[48,50]$. The activation of a $4 \beta 2 \mathrm{nAChRs}$ with partial and full agonists promotes the firing rate $[51,52]$ and facilitates burst firing [52] in VTA DA neurons.

Klink et al. [47] coupled single-cell PCR with electrophysiological recordings and further divided a $4 \beta 2$-containing $n A C h R s$ into two subtypes: a4a5a6 32 -containing $n A C h R s$ (sensitive to both dihydro- $\beta$-erythroidine and $\alpha$-conotoxin MII) and $a 4 a 5 \beta 2$ containing nAChRs (sensitive to dihydro- $\beta$-erythroidine, but not to a-conotoxin MII). The presence of the a5 subunit facilitates the assembly of a4 nAChRs, increases the levels of a4 subunitcontaining $\mathrm{nAChRs}$ by $60 \%$, and slows down the desensitization of these nAChRs in the VTA [53]. Conversely, a loss-of-function mutation in the a5 subunit or the knock-out of the a5 subunit dramatically reduces the nicotine sensitivity of $n A C h R s$, and in these situations, higher levels of nicotine intake are required to induce rewarding effects [54-59].

A bacterial artificial chromosome (BAC)-based genetic modification strategy was employed to introduce gain-of-function a6 subunits ( $\mathrm{Lg}^{\prime} \mathrm{S}$ ) into mice [43]. In this transgenic mouse line, neurons expressing a6-containing $\mathrm{nAChRs}$ are selectively stimulated by low concentrations of nicotine that are unable to excite midbrain DA neurons in wild-type mice. Using this mouse line, Drenan et al. [43] provided functional evidence showing that midbrain DA neurons, but not GABAergic neurons, possess a6-containing nAChRs. Another study demonstrated that either blocking a6-containing nAChRs with a-conotoxin MII [H9A;L15A] or knocking out the a4 subunit reduces the prolonged excitation of VTA DA neurons induced by smokingrelevant concentrations of nicotine (100-500 nM) [60]. Thus, the a4 and a6 subunits are necessary for the nicotine-induced excitation of VTA DA neurons.

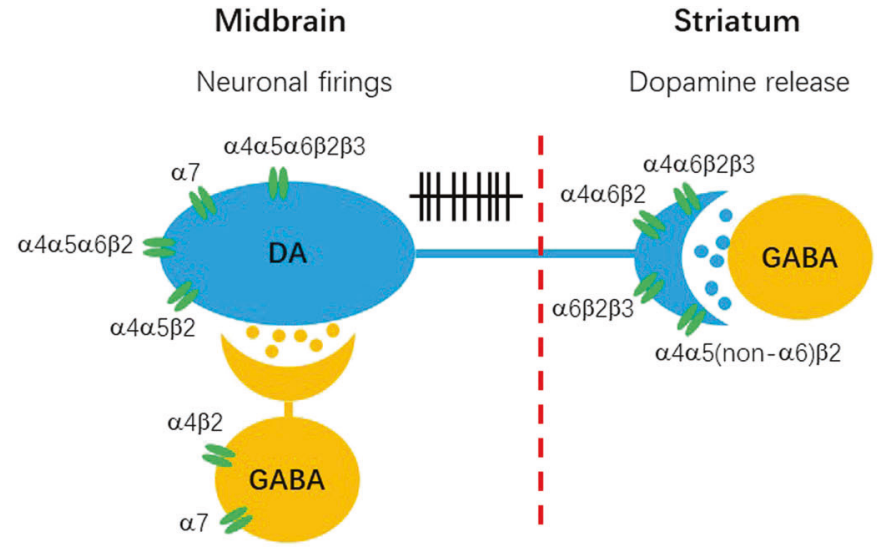

Fig. $3 \mathrm{nAChR}$ subtypes in midbrain neurons and their striatal terminals regulate rodent behaviors. $\mathrm{nAChRs}$ in midbrain DA (cyan) and GABAergic (yellow) neurons integrate to modulate the activity of DA neurons. nAChRs in striatal DA terminals determine the activitydependent gating of dopamine release onto medium spiny neurons (yellow). Nicotine activates nAChRs in midbrain neurons and striatal DA terminals to cause nicotine reward and reinforcement 
Therefore, the major nAChR subtypes that mediate the nicotinic excitation of midbrain DA neurons contain $a 4 a 5 a 6 \beta 2$ and a $4 a 5 \beta 2$ subunits (Fig. 3 ).

Stoichiometry of nAChRs in midbrain DA neurons. In addition to subunit composition, the stoichiometry of nAChRs (i.e., the number of $\alpha$ - and $\beta$-subunits, specifically, $a(3) \beta(2)$ or $a(2) \beta(3)$ ) also affects receptor function. In in vitro heterologous expression systems, the ratio of a4 to $\beta 2 \mathrm{nAChR}$ subunits being transfected was adjusted from $1: 10$ to $10: 1$ by researchers to shift the stoichiometry from almost pure $a 4(2) \beta 2(3)$ to almost pure $a 4(3) \beta 2$ (2) [61-63]. These studies revealed that, compared with a4(3) $\beta 2(2)$ nAChRs, a4(2) $32(3)$ nAChRs have higher sensitivity to nicotinic agonists (nicotine, ACh and TC-2559), lower sensitivity to epibatidine and cytisine, smaller nicotinic and ACh currents, and more evident desensitization upon nicotine exposure. Thus, highsensitivity nAChRs are those responsive to submicromolar concentrations of nicotine obtained from cigarette smoking.

Subtypes of $n A C h R s$ in mesostriatal DA terminals

Like nAChRs in midbrain DA neuron somata, those in striatal DA terminals contain a6 subunits $[43,64]$. In the striatum (including the NAcc and the $\mathrm{CPu}$ ), both $a 4 a 6 \beta 2 \beta 3$ and $a 4 a 6 \beta 2 \mathrm{nAChRs}$ are detected $[50,64]$. In $\beta 3$ subunit knock-out mice, there are $76 \%$ fewer a6 subunits in the striatum, and respectively $34 \%$ and $42 \%$ fewer $a 3$ and $a 6$ subunits in the midbrain, than in wild-type mice, indicating that $\beta 3$ subunits increase the incorporation of a6 subunits into a4 $\beta 2$-containing $n A C h R s$ [64]. The a-conotoxin analog E11A ( $\alpha-C t x M I I-E 11 A$ ) binds primarily to $a 6 a 4 \beta 2 \beta 3$ and a6 $\beta 2 \beta 3 \mathrm{nAChRs}$ in striatal DA terminals with a femtomolar and a picomolar affinity, respectively [65]. Compared with VTA DA neurons, SNc DA neurons are more susceptible to lesions by neurotoxins such as MPTP and 6-OHDA [66]. The fact that a6a4 $32 \beta 3$ nAChRs are more vulnerable to MPTP-induced lesions than $a 6 \beta 2 \beta 3$ nAChRs [65] supports the notion that $a 6 a 4 \beta 2 \beta 3$ $n A C h R s$, but not $a 6 \beta 2 \beta 3$ nAChRs, are among the major nAChRs in DA terminals originating from the SNc.

The magnitude of electrical stimulation-induced dopamine release exhibits regional differences: it is larger in the ventral striatum (the NAcc) than in the dorsal striatum (the $\mathrm{CPu}$ ) [67-69]. Nicotine modulates dopamine release through two opposite mechanisms. After a short period of exposure, nicotine activates presynaptic nAChRs on DA terminals and enhances dopamine release evoked by low-frequency stimulation (mimicking tonic activity of DA neurons) in the striatum, whereas after longer exposure, nicotine desensitizes $\mathrm{nAChRs}$ and reduces dopamine release evoked by single stimulation, but amplifies dopamine release evoked by high-frequency (mimicking burst/phasic firing) electrical stimulation [69, 70]. This contrast suggests that the desensitization of $\mathrm{nAChRs}$ in DA terminals may play important roles in nicotine reinforcement.

It has been demonstrated that $a 4 a 6 \beta 2$ nAChRs and a4(non-a6) $\beta 2 \mathrm{nAChRs}$ are major receptors that, respectively, mediate the nicotinic regulation of dopamine release into the NAcc and the $\mathrm{CPu}[67,71]$. However, an assay of a-conotoxin analog E11A (a(txMII-E11A) binding [65] showed that there are a6a4 $\beta 2 \beta 3$ $\mathrm{nAChRs}$ in DA terminals in the CPu. Further investigations are warranted to address why a6a $4 \beta 2 \beta 3$ nAChRs significantly regulate dopamine release in the NAcc, but not in the CPu.

\section{CHRONIC NICOTINE UPREGULATES NACHR SUBUNITS IN BOTH NUMBER AND FUNCTION}

Acute exposure to nicotine activates nAChRs, while chronic nicotine exposure modifies nAChRs, conferring various physiological outcomes. Chronic nicotine exposure regimens include continuous nicotine administration [72-74], repeated intermittent exposure [75], self-administration [76], and yoked-nicotine administration [74]. To evaluate the effects of chronic nicotine on nAChRs, the levels of nAChRs were quantified with an epibatidine/nicotine binding assay $[74,75,77]$ and by studying the levels of fluorescent protein-tagged nAChR subunits [72, 76]. Under different exposure paradigms, chronic nicotine similarly upregulates $\mathrm{nAChRs}$, but with selectivity for nAChR subtypes, the stoichiometry of nAChRs, cell types, and cell compartments $[72,73,78,79]$.

Chronic nicotine increases the levels of $n A C h R$ subunits

To enable the visualization and quantification of $n A C h R s$ containing a4 subunits in mice and to examine the dynamic alteration of these receptors during nicotine addiction and in different developmental stages, Nashmi et al. [72, 78] developed knock-in mice in which the a $4 \mathrm{nAChR}$ subunit is replaced with normally functioning and fluorescently tagged subunits (a4-eYFP). They found that chronic nicotine did not change a4-containing nAChRs in midbrain DA neurons but upregulated a4-containing $n A C h R s$ in midbrain GABAergic neurons and in the dorsal striatum [72]. Using the same mouse line, Renda et al. [76] exposed mice of different ages to a two-bottle choice oral nicotine self-administration paradigm for 5 days. They found that the amount of nicotine selfadministered was significantly higher in 44-day-old and 54-60day-old mice than in 66-86-day-old mice and that it showed a strong-positive correlation with the levels of a4-eYFP [76].

In comparison with a $4 \beta 2$ nAChRs, a6 $\beta 2$, a3 32 , and a7 nAChRs are less sensitive in terms of being upregulated by chronic nicotine $[77,80,81]$. Although a5 subunits facilitate the assembly of a $4 \beta 2$ nAChRs, they attenuate the chronic nicotine-induced upregulation of $a 4 \beta 2$ nAChRs [82]. In striatal DA terminals, a6 $\beta 2-$ containing $\mathrm{nAChRs}$ are downregulated by chronic exposure to nicotine at a concentration threefold lower than that required to upregulate $\alpha 4 \beta 2$-containing $n A C h R s$ [83].

Chronic nicotine also alters the stoichiometry of nAChRs Several studies have revealed that chronic nicotine treatment enhances cationic currents evoked by $1 \mu \mathrm{M}$ nicotine or 3-30 $\mu \mathrm{M}$ ACh in SNr GABAergic neurons but not in SNc DA neurons [72, 73]. This finding suggests that chronic nicotine can bias the stoichiometry of nAChRs to high-sensitivity $(a(2) \beta(3))$ ones. This notion is also consistent with previous in vitro studies showing that nicotine more efficiently upregulates a4(2)B2(3) nAChRs than $a 4(3) \beta 2(2)$ nAChRs [61-63]. The effects of chronic nicotine treatment on the biophysical properties of $\mathrm{nAChRs}$ are controversial. Buisson and Bertrand [61] showed that $\alpha 4(2) \beta 2(3)$ nAChRs exhibit larger single-channel conductance and slower desensitization kinetics, but Lopez-Hernandez et al. [62] showed that a4(2) $\beta 2$ (3) nAChRs mediate smaller currents and display more evident desensitization upon acute nicotine exposure.

Gain-of-function a4 (L9'S) subunits were transduced into mouse VTA GABAergic neurons to directly enhance a4-containing $n A C h R$ function in these neurons, mimicking the chronic nicotine effect (upregulating $\mathrm{nAChRs}$ in number and sensitivity) [84]. This strategy increased the sensitivity of nAChRs to nicotine in GABAergic neurons, and conditioned place preference was induced by low concentrations of nicotine in these mice [84]. The results suggest that the cell-type selective upregulation of a4-containing nAChRs by chronic nicotine can promote nicotine-seeking behaviors.

NACHR SUBTYPES ARE INVOLVED IN NICOTINE DEPENDENCE Nicotine dependence is a chronically relapsing behavioral disorder with typical manifestations of drug addiction, such as compulsive cravings for nicotine, a loss of control to limit nicotine intake, and withdrawal-like symptoms after access to nicotine is prevented $[2,85]$. The rewarding and reinforcing effects of nicotine involve midbrain neurons and can be measured with nicotine-conditioned place preference and nicotine self-administration $[2,85]$. 
Withdrawal symptoms after nicotine abstinence are regulated by the extended amygdala and MHb-IPN pathway [85, 86]. Accumulating evidence has shown that different subtypes of nAChRs play distinct roles in the effects of nicotine.

\section{a4 nAChRs}

A nicotine-conditioned place preference (CPP) paradigm was used in two genetic mouse lines, one lacking the a4 subunit (a4 knockout) and one carrying a gain-of-function mutation in the a4 subunit (a4 L9'A) [87]. The knock-out of a4 nAChRs eliminated responses to smoking-relevant concentrations of nicotine in VTA neurons, while a4 L9'A-containing nAChRs enabled the excitation of VTA neurons by nicotine at concentrations much lower than those achieved by cigarette smoking [87]. Consistently, the administration of nicotine at the concentration that establishes CPP in wild-type mice did not establish CPP in a4 knock-out mice, but nicotine induced CPP in a4 $\left(\mathrm{L9}^{\prime} \mathrm{A}\right)$ mice at a much lower concentration [87]. As the $n A C h R s$ of these mice are modified throughout the entire brain, the results may be inadequate to conclude that the contributing a4 $\mathrm{nAChRs}$ are in midbrain DA neurons. Conditionally deleting a $4 \mathrm{nAChRs}$ in the ventral midbrain using a viral vector-assisted Cre/loxP approach, Peng et al. [88] revealed that mice lacking a4 $\mathrm{nAChRs}$ in the ventral midbrain consumed more nicotine but did not exhibit nicotine CPP. These results seem contradictory, but the authors argue that the lack of a4 nAChRs may attenuate nicotine-induced aversive effects but increase the amount of nicotine required to stimulate the reward system. McGranahan et al. [89] restricted the genetic deletion of a4 subunits to DA neurons in mice without perturbing a4 nAChRs in GABAergic neurons. This manipulation eliminated nicotine CPP. The results further demonstrated that a 4 nAChRs in DA neurons are necessary for the development of nicotine-seeking behavior.

\section{$\beta 2 \mathrm{nAChRs}$}

a4 and $\beta 2$ subunits form the major $n A C h R$ subtype in the midbrain and mediate the reinforcing effects of nicotine [46-49]. The genetic modification of the $\beta 2$ subunit has similar effects as that of the a4 subunit. It has been demonstrated that $\beta 2 \mathrm{nAChRs}$ are necessary to mediate nicotine responses in midbrain neurons, and knocking out these nAChRs dramatically reduces nicotine selfadministration [90]. The re-expression of the $\beta 2$ subunit in VTA neurons of $\beta 2$ subunit knock-out mice restores nicotine-induced responses, including the excitation of VTA DA neurons, an increase in dopamine release in the NAcc, and nicotine self-administration [91, 92].

Several mechanisms may underlie the nicotine-induced stimulation of VTA DA neurons [35, 87, 90, 92-94]. First, nicotine directly activates nAChRs on DA neurons. Second, nicotine desensitizes $n A C h R s$ on local GABAergic neurons, leading to the disinhibition of DA neurons. Third, nicotine activates nAChRs in glutamatergic terminals that synapse onto DA neurons to cause the sustained excitation of DA neurons. An elegant study employed a cellspecific viral-vector strategy to re-express the $\beta 2$ subunit in either VTA DA neurons, GABAergic neurons or both in $\beta 2$ subunit knockout mice and revealed that, in this mouse line, nicotine respectively excites, inhibits and enhances burst firing in VTA DA neurons in vivo and correspondingly causes transient rewarding, aversive, and reinforcing effects [95]. Their data suggest that the induction of burst firing in VTA DA neurons might be a prerequisite for the establishment of nicotine self-administration and requires the activation of $\beta 2 \mathrm{nAChRs}$ on both DA and GABAergic neurons.

a4 and a6 nAChRs

In the VTA, the a6 subunit is selectively expressed in DA neurons [41-45]. Exley et al. [96] demonstrated that the a4 and a6 subunits play different roles in the reinforcing effect of nicotine. Their data showed that nAChR a4 subunits are required to establish intracranial nicotine self-administration and to induce burst firing in VTA DA neurons, whereas both the $a 4$ and a6 subunits are involved in the regulation of activity-dependent dopamine release in the NAcc. Therefore, a4 subunit-containing nAChRs in VTA DA neuron somata and $a 4$ and a6 subunit-containing nAChRs in DA terminals in the NAcC control the activity of DA neurons and the release of dopamine, respectively. These two processes may, respectively, underlie nicotine self-administration and its longterm maintenance [96].

\section{a5-a3- $\beta 4$ nAChRs}

The genes that encode the $a 5, a 3$, and $\beta 4 n A C h R$ subunits form a cluster in chromosome region $15 q 25$, and some allelic variations in this gene cluster are risk factors for nicotine dependence $[97,98]$. A single-nucleotide polymorphism (SNP) in the a5 subunit gene (CHRNA5) (rs16969968) increases the incidence of tobacco dependence, heavy smoking, and the early onset of smoking behaviors [97-100]. SNPs that have similar effects on nicotine dependence include rs6495308, rs578776, and rs1051730 in the a3 subunit gene (CHRNA3) [97, 101, 102] and rs1948 in the $\beta 4$ subunit gene (CHRNB4) [103]. Consistent with these epidemiological studies, the knock-out of the a5 subunit increases nicotine self-administration in mice [86]. Although $a 5, a 3$, and $\beta 4$ $n A C h R$ subunits are expressed in some midbrain DA neurons, the levels are much lower than those in the MHb and IPN [104]. Furthermore, the re-expression of the a5 subunit in the MHb-IPN pathway in a5 knock-out mice reverses the enhancement of nicotine self-administration [86]. Therefore, a5 nAChRs in the $\mathrm{MHb}-\mathrm{IPN}$ pathway play critical roles in nicotine intake.

Both systemic and intra-IPN administration of mecamylamine, an antagonist of nAChRs, precipitates withdrawal symptoms in nicotine-dependent animals, but not in a5 and a 2 knock-out mice [105], supporting the notion that a5 nAChRs in the MHb-IPN pathway regulate the expression of withdrawal symptoms in nicotine-dependent animals.

\begin{tabular}{|c|c|c|c|c|}
\hline Region & Neurochemistry & $\begin{array}{l}\text { nAChR } \\
\text { subunits }\end{array}$ & $\begin{array}{l}\text { nAChR } \\
\text { subtypes }\end{array}$ & Chronic nicotine \\
\hline \multirow[t]{4}{*}{ VTA } & \multirow[t]{3}{*}{ DA neurons } & $\begin{array}{l}\text { All have } \alpha 2 \text {, } \\
\alpha 4, \alpha 5 \text {, } \\
\alpha 6, \beta 2, \beta 3\end{array}$ & $\begin{array}{l}\alpha 4 \beta 2: \\
\alpha 4 \alpha 5 \alpha 6 \beta 2\end{array}$ & No change \\
\hline & & $\begin{array}{l}\text { Some } \\
\text { have } \alpha 3, \alpha 7\end{array}$ & $\alpha 7$ & No change \\
\hline & & Few have $\beta 4$ & $\alpha 3 \beta 4$ & No change \\
\hline & GABA neurons & $\begin{array}{l}\alpha 4, \\
\beta 2, \beta 3, \alpha 7\end{array}$ & $\begin{array}{l}\alpha 4 \beta 2 \\
\alpha 7\end{array}$ & $\begin{array}{l}\text { Upregulation } \\
\text { No change }\end{array}$ \\
\hline \multirow[t]{4}{*}{ SNc } & \multirow[t]{3}{*}{ DA neurons } & $\begin{array}{l}\text { All have } \alpha 2 \text {, } \\
\alpha 4, \alpha 5 \\
\alpha 6, \beta 2, \beta 3\end{array}$ & $\alpha 4 \beta 2$ & No change \\
\hline & & $\begin{array}{l}\text { Some } \\
\text { have } \alpha 3, \alpha 7\end{array}$ & $\alpha 4 \alpha 5 \alpha 6 \beta 2$ & No change \\
\hline & & Few have $\beta 4$ & $\alpha 7$ & No change \\
\hline & GABA neurons & $\begin{array}{l}\alpha 4, \beta 2 \\
\beta 3, \text { and } \alpha 7\end{array}$ & $\begin{array}{l}\alpha 4 \beta 2 \\
\alpha 7\end{array}$ & $\begin{array}{l}\text { Upregulation } \\
\text { No change }\end{array}$ \\
\hline NAcc & DA terminals & $\begin{array}{l}\alpha 4, \\
\alpha 6, \beta 2, \beta 3\end{array}$ & $\begin{array}{l}\alpha 4 \alpha 6 \beta 2 \\
\alpha 6 \beta 2 \beta 3\end{array}$ & $\begin{array}{l}\text { Downregulation } \\
\text { Downregulation }\end{array}$ \\
\hline $\mathrm{CPu}$ & DA terminals & $\begin{array}{l}\alpha 4, \alpha 5, \\
\alpha 6, \beta 2, \beta 3\end{array}$ & $\begin{array}{l}\alpha 4 \alpha 6 \beta 2 \beta 3 \\
\alpha 4 \alpha 6 \beta 2 \\
\alpha 4 \alpha 5 \text { (non- } \\
\alpha 6) \beta 2\end{array}$ & $\begin{array}{l}\text { Downregulation } \\
\text { Downregulation } \\
\text { Upregulation }\end{array}$ \\
\hline
\end{tabular}


In conclusion, the cholinergic modulation of midbrain DA neurons relies on the topographic organization of PPN and LDT cholinergic projections (Fig. 2) and the activation of cholinergic receptors in midbrain DA neurons and their terminals in the NAcc and $\mathrm{CPu}$ (Fig. 3 and Table 1). nAChRs in midbrain DA neurons and GABAergic neurons are involved in the regulation of firing rates and patterns of DA neurons. In this process, the contributing nAChRs in DA neurons may contain $\alpha 4, \beta 2, \alpha 6$, and $\alpha 7$ subunits, while those in GABAergic neurons express $\alpha 4, \beta 2$, and $\alpha 7$ subunits. It is noteworthy that a4 $\beta 2 \mathrm{nAChRs}$ in midbrain GABAergic neurons have been revealed to play critical roles in the nicotine-induced sustained enhancement of firing rates and bursting firing patterns. The latter is essential for the development of nicotine selfadministration. On the other hand, nAChRs containing $\alpha 4, \beta 2$, a6 subunits on striatal DA terminals provide a gating mechanism for the adjustment of activity-dependent dopamine release, which is important for maintaining long-term nicotine intake. Therefore, the $a 4, \beta 2$, a6 subunits mediate the effect of nicotine on reward processing and reinforcement learning and are involved in nicotine dependence.

Currently available drugs for smoking cessation include nicotine, partial agonists of nAChRs (cytisine and varenicline), and bupropion [106]. Partial agonists are used because they can moderately activate nAChRs to obtain normal levels of dopamine to reduce nicotine withdrawal symptoms, but the increase in dopamine levels is insufficient to cause satisfaction as strong as that induced by nicotine [107]. Among these drugs, varenicline, a partial agonist of $\beta 2$-containing $n A C h R s$ and a full agonist of a7and $a 3 \beta 4$-containing $n A C h R s$, has the highest success rate for smoking cessation [106]. On the one hand, acute varenicline can mildly activate $\alpha 4 \beta 2$ - and a6ß2-containing $\mathrm{nAChRs}$, and a7 $\mathrm{nAChRs}$, attenuating nicotine withdrawal symptoms and reducing motivation for nicotine intake [108]. On the other hand, chronic varenicline upregulates $\alpha 4 \beta 2 \mathrm{nAChRs}$ in a manner similar to that of chronic nicotine, but it also upregulates a3 $\beta 4$ and $\alpha 7 \mathrm{nAChRs}$ [109]. This pattern may mitigate dysfunction of the midbrain circuit following the selective upregulation of $\alpha 4 \beta 2$ nAChRs in GABAergic neurons by chronic nicotine.

Therefore, a4 $\beta 2$ - and a6 32 -containing nAChRs in the midbrain DA system are effective targets for smoking cessation. However, other subunits with relatively lower expression levels, such as the $\alpha 7, \alpha 3, \alpha 5, \beta 3$, and $\beta 4$ subunits, should be considered in future investigations because these subunits have been reported to regulate the $a 4, a 6$, and $\beta 2$ subunits. Novel drugs that are more specific for $n A C h R$ subtypes should be designed to minimize the unpleasant side-effects of currently available drugs for smoking cessation, including nausea and depressed mood [1].

\section{ACKNOWLEDGEMENTS}

This work was supported by the National Natural Science Foundation of China (81701100, 81870891), the Fund for Jiangsu Province Specially Appointed Professor (CX, CZ), the Natural Science Foundation of Jiangsu Province (BK20171160), the Natural Science Foundation of the Jiangsu Higher Education Institutions of China (17KJA320007, 18KJA320009), and the Jiangsu Province Fund for Dominant Discipline (Anesthesiology).

\section{ADDITIONAL INFORMATION}

Competing interests: The authors declare no competing interests.

\section{REFERENCES}

1. Wipfli $\mathrm{H}$, Samet JM. One hundred years in the making: the global tobacco epidemic. Annu Rev Public Health. 2016;37:149-66.

2. De Biasi M, Dani JA. Reward, addiction, withdrawal to nicotine. Annu Rev Neurosci. 2011;34:105-30.

3. Morales $M$, Margolis EB. Ventral tegmental area: cellular heterogeneity, connectivity and behaviour. Nat Rev Neurosci. 2017;18:73-85.
4. Matsumoto H, Tian J, Uchida N, Watabe-Uchida M. Midbrain dopamine neurons signal aversion in a reward-context-dependent manner. Elife. 2016;5. pii:e17328.

5. Dautan D, Souza AS, Huerta-Ocampo I, Valencia M, Assous M, Witten IB, et al. Segregated cholinergic transmission modulates dopamine neurons integrated in distinct functional circuits. Nat Neurosci. 2016;19:1025-33.

6. Mena-Segovia J, Bolam JP. Rethinking the pedunculopontine nucleus: from cellular organization to function. Neuron. 2017;94:7-18.

7. Mena-Segovia J, Winn P, Bolam JP. Cholinergic modulation of midbrain dopaminergic systems. Brain Res Rev. 2008;58:265-71.

8. Xiao C, Cho JR, Zhou C, Treweek JB, Chan K, McKinney SL, et al. Cholinergic mesopontine signals govern locomotion and reward through dissociable midbrain pathways. Neuron. 2016;90:333-47.

9. Estakhr J, Abazari D, Frisby K, McIntosh JM, Nashmi R. Differential control of dopaminergic excitability and locomotion by cholinergic inputs in mouse substantia nigra. Curr Biol. 2017;27:1900-14 e4.

10. Benarroch EE. Pedunculopontine nucleus: functional organization and clinical implications. Neurology. 2013;80:1148-55.

11. Garcia-Rill E, Simon C, Smith K, Kezunovic N, Hyde J. The pedunculopontine tegmental nucleus: from basic neuroscience to neurosurgical applications: arousal from slices to humans: implications for DBS. J Neural Transm (Vienna). 2011;118:1397-407.

12. Roseberry TK, Lee AM, Lalive AL, Wilbrecht L, Bonci A, Kreitzer AC. Cell-typespecific control of brainstem locomotor circuits by basal ganglia. Cell. 2016;164:526-37.

13. Dineley KT, Pandya AA, Yakel JL. Nicotinic ACh receptors as therapeutic targets in CNS disorders. Trends Pharmacol Sci. 2015;36:96-108.

14. Wu J. Understanding of nicotinic acetylcholine receptors. Acta Pharmacol Sin. 2009;30:653-5.

15. Lebois EP, Thorn C, Edgerton JR, Popiolek M, Xi S. Muscarinic receptor subtype distribution in the central nervous system and relevance to aging and Alzheimer's disease. Neuropharmacology. 2018;136:362-73.

16. Good CH, Lupica CR. Properties of distinct ventral tegmental area synapses activated via pedunculopontine or ventral tegmental area stimulation in vitro. J Physiol. 2009;587:1233-47.

17. Futami T, Takakusaki K, Kitai ST. Glutamatergic and cholinergic inputs from the pedunculopontine tegmental nucleus to dopamine neurons in the substantia nigra pars compacta. Neurosci Res. 1995;21:331-42.

18. Wang $\mathrm{HL}$, Morales $\mathrm{M}$. Pedunculopontine and laterodorsal tegmental nuclei contain distinct populations of cholinergic, glutamatergic and GABAergic neurons in the rat. Eur J Neurosci. 2009;29:340-58.

19. Lammel S, Lim BK, Ran C, Huang KW, Betley MJ, Tye KM, et al. Input-specific control of reward and aversion in the ventral tegmental area. Nature. 2012;491:212.

20. Lavoie B, Parent A. Pedunculopontine nucleus in the squirrel monkey: cholinergic and glutamatergic projections to the substantia nigra. J Comp Neurol. 1994;344:232-41.

21. Oakman SA, Faris PL, Kerr PE, Cozzari C, Hartman BK. Distribution of pontomesencephalic cholinergic neurons projecting to substantia nigra differs significantly from those projecting to ventral tegmental area. J Neurosci. 1995;15:5859-69.

22. Ren J, Qin C, Hu F, Tan J, Qiu L, Zhao S, et al. Habenula "cholinergic" neurons corelease glutamate and acetylcholine and activate postsynaptic neurons via distinct transmission modes. Neuron. 2011;69:445-52.

23. Picciotto MR, Kenny PJ. Molecular mechanisms underlying behaviors related to nicotine addiction. Cold Spring Harb Perspect Med. 2013;3:a012112.

24. Mark GP, Shabani S, Dobbs LK, Hansen ST. Cholinergic modulation of mesolimbic dopamine function and reward. Physiol Behav. 2011;104:76-81.

25. Forster GL, Blaha CD. Laterodorsal tegmental stimulation elicits dopamine efflux in the rat nucleus accumbens by activation of acetylcholine and glutamate receptors in the ventral tegmental area. Eur J Neurosci. 2000;12:3596-604.

26. Forster $\mathrm{GL}$, Blaha $\mathrm{CD}$. Pedunculopontine tegmental stimulation evokes striatal dopamine efflux by activation of acetylcholine and glutamate receptors in the midbrain and pons of the rat. Eur J Neurosci. 2003;17:751-62.

27. Clarke PB, Hommer DW, Pert A, Skirboll LR. Innervation of substantia nigra neurons by cholinergic afferents from pedunculopontine nucleus in the rat: neuroanatomical and electrophysiological evidence. Neuroscience. 1987;23:1011-9.

28. Jose Lanca A, Sanelli TR, Corrigall WA. Nicotine-induced fos expression in the pedunculopontine mesencephalic tegmentum in the rat. Neuropharmacology. 2000;39:2808-17.

29. Lanca AJ, Adamson KL, Coen KM, Chow BL, Corrigall WA. The pedunculopontine tegmental nucleus and the role of cholinergic neurons in nicotine selfadministration in the rat: a correlative neuroanatomical and behavioral study. Neuroscience. 2000;96:735-42.

30. Raffa RB. The M5 muscarinic receptor as possible target for treatment of drug abuse. J Clin Pharm Ther. 2009;34:623-9. 
31. Steidl S, Miller AD, Blaha CD, Yeomans JS. M(5) muscarinic receptors mediate striatal dopamine activation by ventral tegmental morphine and pedunculopontine stimulation in mice. PLoS One. 2011;6:e27538.

32. Weiner DM, Levey Al, Brann MR. Expression of muscarinic acetylcholine and dopamine receptor mRNAs in rat basal ganglia. Proc Natl Acad Sci USA. 1990;87:7050-4.

33. Fisher JL, Pidoplichko VI, Dani JA. Nicotine modifies the activity of ventral tegmental area dopaminergic neurons and hippocampal GABAergic neurons. J Physiol Paris. 1998;92:209-13.

34. Mansvelder HD, De Rover M, McGehee DS, Brussaard AB. Cholinergic modulation of dopaminergic reward areas: upstream and downstream targets of nicotine addiction. Eur J Pharmacol. 2003;480:117-23.

35. Mansvelder HD, McGehee DS. Long-term potentiation of excitatory inputs to brain reward areas by nicotine. Neuron. 2000;27:349-57.

36. Keath JR, lacoviello MP, Barrett LE, Mansvelder HD, McGehee DS. Differential modulation by nicotine of substantia nigra versus ventral tegmental area dopamine neurons. J Neurophysiol. 2007;98:3388-96.

37. Mereu G, Yoon KW, Boi V, Gessa GL, Naes L, Westfall TC. Preferential stimulation of ventral tegmental area dopaminergic neurons by nicotine. Eur J Pharmacol. 1987;141:395-9.

38. Teo MY, van Wyk M, Lin J, Lipski J. Differential effects of nicotine on the activity of substantia nigra and ventral tegmental area dopaminergic neurons in vitro. Acta Neurobiol Exp (Wars). 2004;64:119-30.

39. Azam L, Winzer-Serhan UH, Chen Y, Leslie FM. Expression of neuronal nicotinic acetylcholine receptor subunit mRNAs within midbrain dopamine neurons. J Comp Neurol. 2002;444:260-74.

40. Charpantier E, Barneoud P, Moser P, Besnard F, Sgard F. Nicotinic acetylcholine subunit mRNA expression in dopaminergic neurons of the rat substantia nigra and ventral tegmental area. Neuroreport. 1998;9:3097-101.

41. Le Novere N, Zoli M, Changeux JP. Neuronal nicotinic receptor alpha 6 subunit mRNA is selectively concentrated in catecholaminergic nuclei of the rat brain. Eur J Neurosci. 1996;8:2428-39.

42. Berry JN, Engle SE, McIntosh JM, Drenan RM. alpha6-Containing nicotinic acetylcholine receptors in midbrain dopamine neurons are poised to govern dopamine-mediated behaviors and synaptic plasticity. Neuroscience. 2015;304:161-75.

43. Drenan RM, Grady SR, Whiteaker P, McClure-Begley T, McKinney S, Miwa JM, et al. In vivo activation of midbrain dopamine neurons via sensitized, highaffinity alpha 6 nicotinic acetylcholine receptors. Neuron. 2008;60:123-36.

44. Goldner FM, Dineley KT, Patrick JW. Immunohistochemical localization of the nicotinic acetylcholine receptor subunit alpha6 to dopaminergic neurons in the substantia nigra and ventral tegmental area. Neuroreport. 1997;8:2739-42.

45. Emmett SR, Greenfield SA. Correlation between dopaminergic neurons, acetylcholinesterase and nicotinic acetylcholine receptors containing the alpha3- or alpha5-subunit in the rat substantia nigra. J Chem Neuroanat. 2005;30:34-44.

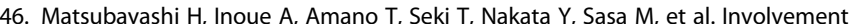
of alpha7- and alpha4beta2-type postsynaptic nicotinic acetylcholine receptors in nicotine-induced excitation of dopaminergic neurons in the substantia nigra: a patch clamp and single-cell PCR study using acutely dissociated nigral neurons. Brain Res Mol Brain Res. 2004;129:1-7.

47. Klink R, de Kerchove d'Exaerde A, Zoli M, Changeux JP. Molecular and physiological diversity of nicotinic acetylcholine receptors in the midbrain dopaminergic nuclei. J Neurosci. 2001;21:1452-63.

48. Wooltorton JR, Pidoplichko VI, Broide RS, Dani JA. Differential desensitization and distribution of nicotinic acetylcholine receptor subtypes in midbrain dopamine areas. J Neurosci. 2003;23:3176-85.

49. Yang $\mathrm{K}$, Hu J, Lucero $\mathrm{L}$, Liu $\mathrm{Q}$, Zheng $C$, Zhen $X$, et al. Distinctive nicotinic acetylcholine receptor functional phenotypes of rat ventral tegmental area dopaminergic neurons. J Physiol. 2009;587:345-61.

50. Champtiaux N, Gotti C, Cordero-Erausquin M, David DJ, Przybylski C, Lena C, et al. Subunit composition of functional nicotinic receptors in dopaminergic neurons investigated with knock-out mice. J Neurosci. 2003;23:7820-9.

51. Chen Y, Broad LM, Phillips KG, Zwart R. Partial agonists for alpha4beta2 nicotinic receptors stimulate dopaminergic neuron firing with relatively enhanced maximal effects. Br J Pharmacol. 2012;165:1006-16.

52. Wang Y, Sherwood JL, Miles CP, Whiffin G, Lodge D. TC-2559 excites dopaminergic neurones in the ventral tegmental area by stimulating alpha4beta2-like nicotinic acetylcholine receptors in anaesthetised rats. $\mathrm{Br} J$ Pharmacol. 2006;147:379-90.

53. Chatterjee $\mathrm{S}$, Santos $\mathrm{N}$, Holgate J, Haass-Koffler CL, Hopf FW, Kharazia V, et al. The alpha5 subunit regulates the expression and function of alpha $4{ }^{*}$-containing neuronal nicotinic acetylcholine receptors in the ventral-tegmental area. PLoS One. 2013;8:e68300.
54. Deflorio C, Blanchard S, Carisi MC, Bohl D, Maskos U. Human polymorphisms in nicotinic receptors: a functional analysis in iPS-derived dopaminergic neurons. FASEB J. 2017;31:828-39.

55. Forget $B$, Scholze $P$, Langa $F$, Morel $C$, Pons $S$, Mondoloni $S$, et al. A Human polymorphism in CHRNA5 is linked to relapse to nicotine seeking in transgenic rats. Curr Biol. 2018:28:3244-53 e7.

56. Grieder TE, George O, Yee M, Bergamini MA, Chwalek M, Maal-Bared G, et al. Deletion of alpha5 nicotine receptor subunits abolishes nicotinic aversive motivational effects in a manner that phenocopies dopamine receptor antagonism. Eur J Neurosci. 2017;46:1673-81.

57. Koukouli F, Rooy M, Tziotis D, Sailor KA, O’Neill HC, Levenga J, et al. Nicotine reverses hypofrontality in animal models of addiction and schizophrenia. Nat Med. 2017;23:347-54

58. Liu XA, Kenny PJ. alpha5 nicotinic receptors link smoking to schizophrenia. Nat Med. 2017;23:277-8.

59. Morel C, Fattore L, Pons S, Hay YA, Marti F, Lambolez B, et al. Nicotine consumption is regulated by a human polymorphism in dopamine neurons. Mol Psychiatry. 2014;19:930-6.

60. Liu L, Zhao-Shea R, McIntosh JM, Gardner PD, Tapper AR. Nicotine persistently activates ventral tegmental area dopaminergic neurons via nicotinic acetylcholine receptors containing alpha4 and alpha6 subunits. Mol Pharmacol. 2012;81:541-8

61. Buisson B, Bertrand D. Chronic exposure to nicotine upregulates the human (alpha)4((beta)2 nicotinic acetylcholine receptor function. J Neurosci. 2001;21:1819-29.

62. Lopez-Hernandez GY, Sanchez-Padilla J, Ortiz-Acevedo A, Lizardi-Ortiz J, SalasVincenty J, Rojas LV, et al. Nicotine-induced up-regulation and desensitization of alpha4beta2 neuronal nicotinic receptors depend on subunit ratio. J Biol Chem. 2004;279:38007-15.

63. Moroni M, Zwart R, Sher E, Cassels BK, Bermudez I. alpha4beta2 nicotinic receptors with high and low acetylcholine sensitivity: pharmacology, stoichiometry, and sensitivity to long-term exposure to nicotine. Mol Pharmacol. 2006;70:755-68.

64. Gotti C, Moretti M, Clementi F, Riganti L, Mclntosh JM, Collins AC, et al. Expression of nigrostriatal alpha 6-containing nicotinic acetylcholine receptors is selectively reduced, but not eliminated, by beta 3 subunit gene deletion. Mol Pharmacol. 2005;67:2007-15.

65. Bordia T, Grady SR, McIntosh JM, Quik M. Nigrostriatal damage preferentially decreases a subpopulation of alpha6beta2* nAChRs in mouse, monkey, and Parkinson's disease striatum. Mol Pharmacol. 2007;72:52-61.

66. Roeper J. Dissecting the diversity of midbrain dopamine neurons. Trends Neurosci. 2013;36:336-42.

67. Exley R, Clements MA, Hartung H, Mclntosh JM, Cragg SJ. Alpha6-containing nicotinic acetylcholine receptors dominate the nicotine control of dopamine neurotransmission in nucleus accumbens. Neuropsychopharmacology. 2008;33:2158-66.

68. Zhang L, Doyon WM, Clark JJ, Phillips PE, Dani JA. Controls of tonic and phasic dopamine transmission in the dorsal and ventral striatum. Mol Pharmacol. 2009;76:396-404

69. Zhang T, Zhang L, Liang Y, Siapas AG, Zhou FM, Dani JA. Dopamine signaling differences in the nucleus accumbens and dorsal striatum exploited by nicotine. J Neurosci. 2009;29:4035-43.

70. Rice ME, Cragg SJ. Nicotine amplifies reward-related dopamine signals in striatum. Nat Neurosci. 2004;7:583-4.

71. Exley R, Mclntosh JM, Marks MJ, Maskos U, Cragg SJ. Striatal alpha5 nicotinic receptor subunit regulates dopamine transmission in dorsal striatum. J Neurosci. 2012;32:2352-6.

72. Nashmi R, Xiao C, Deshpande P, McKinney S, Grady SR, Whiteaker P, et al. Chronic nicotine cell specifically upregulates functional alpha $4^{*}$ nicotinic receptors: basis for both tolerance in midbrain and enhanced long-term potentiation in perforant path. J Neurosci. 2007;27:8202-18.

73. Xiao C, Nashmi R, McKinney S, Cai H, Mclntosh JM, Lester HA. Chronic nicotine selectively enhances alpha4beta2* nicotinic acetylcholine receptors in the nigrostriatal dopamine pathway. J Neurosci. 2009;29:12428-39.

74. Metaxas A, Bailey A, Barbano MF, Galeote L, Maldonado R, Kitchen I. Differential region-specific regulation of alpha4beta2* $\mathrm{nAChRs}$ by self-administered and non-contingent nicotine in C57BL/6 J mice. Addict Biol. 2010;15:464-79.

75. Baker LK, Mao D, Chi H, Govind AP, Vallejo YF, lacoviello M, et al. Intermittent nicotine exposure upregulates $\mathrm{nAChRs}$ in VTA dopamine neurons and sensitises locomotor responding to the drug. Eur J Neurosci. 2013;37:1004-11.

76. Renda A, Penty N, Komal P, Nashmi R. Vulnerability to nicotine selfadministration in adolescent mice correlates with age-specific expression ofalpha4* nicotinic receptors. Neuropharmacology. 2016;108:49-59. 
77. Walsh H, Govind AP, Mastro R, Hoda JC, Bertrand D, Vallejo Y, et al. Upregulation of nicotinic receptors by nicotine varies with receptor subtype. J Biol Chem. 2008;283:6022-32.

78. Lester HA, Xiao C, Srinivasan R, Son CD, Miwa J, Pantoja R, et al. Nicotine is a selective pharmacological chaperone of acetylcholine receptor number and stoichiometry. Implications for drug discovery. AAPS J. 2009;11:167-77.

79. Nashmi R, Lester H. Cell autonomy, receptor autonomy, and thermodynamics in nicotine receptor up-regulation. Biochem Pharmacol. 2007;74:1145-54.

80. Olale F, Gerzanich V, Kuryatov A, Wang F, Lindstrom J. Chronic nicotine exposure differentially affects the function of humanalpha3, alpha4, and alpha7 neuronal nicotinic receptor subtypes. J Pharmacol Exp Ther. 1997;283:675-83.

81. Peng X, Gerzanich V, Anand R, Wang F, Lindstrom J. Chronic nicotine treatment up-regulates alpha3 and alpha7 acetylcholine receptor subtypes expressed by the human neuroblastoma cell line SH-SY5Y. Mol Pharmacol. 1997;51:776-84.

82. Mao D, Perry DC, Yasuda RP, Wolfe BB, Kellar KJ. The alpha4beta2alpha5 nicotinic cholinergic receptor in rat brain is resistant to up-regulation by nicotine in vivo. J Neurochem. 2008;104:446-56.

83. Marks MJ, Grady SR, Salminen O, Paley MA, Wageman CR, Mclntosh JM, et al. alpha6beta $2 *$-subtype nicotinic acetylcholine receptors are more sensitive than alpha4beta $2^{*}$-subtype receptors to regulation by chronic nicotine administration. J Neurochem. 2014;130:185-98.

84. Ngolab J, Liu L, Zhao-Shea R, Gao G, Gardner PD, Tapper AR. Functional upregulation of alpha $4^{*}$ nicotinic acetylcholine receptors in VTA GABAergic neurons increases sensitivity to nicotine reward. J Neurosci. 2015;35:8570-8.

85. Koob GF, Volkow ND. Neurobiology of addiction: a neurocircuitry analysis. Lancet Psychiatry. 2016;3:760-73.

86. Fowler CD, Lu Q, Johnson PM, Marks MJ, Kenny PJ. Habenular alpha5 nicotinic receptor subunit signalling controls nicotine intake. Nature. 2011;471:597-601.

87. Tapper AR, McKinney SL, Nashmi R, Schwarz J, Deshpande P, Labarca C, et al. Nicotine activation of alpha4* receptors: sufficient for reward, tolerance, and sensitization. Science. 2004;306:1029-32.

88. Peng C, Engle SE, Yan Y, Weera MM, Berry JN, Arvin MC, et al. Altered nicotine reward-associated behavior following alpha4 $\mathrm{nAChR}$ subunit deletion in ventral midbrain. PLoS One. 2017;12:e0182142.

89. McGranahan TM, Patzlaff NE, Grady SR, Heinemann SF, Booker TK. alpha4beta2 nicotinic acetylcholine receptors on dopaminergic neurons mediate nicotine reward and anxiety relief. J Neurosci. 2011;31:10891-902.

90. Picciotto MR, Zoli M, Rimondini R, Lena C, Marubio LM, Pich EM, et al. Acetylcholine receptors containing the beta2 subunit are involved in the reinforcing properties of nicotine. Nature. 1998;391:173-7.

91. Maskos U, Molles BE, Pons S, Besson M, Guiard BP, Guilloux JP, et al. Nicotine reinforcement and cognition restored by targeted expression of nicotinic receptors. Nature. 2005;436:103-7.

92. Mameli-Engvall M, Evrard A, Pons S, Maskos U, Svensson TH, Changeux JP, et al. Hierarchical control of dopamine neuron-firing patterns by nicotinic receptors. Neuron. 2006;50:911-21.

93. Graupner M, Maex R, Gutkin B. Endogenous cholinergic inputs and local circuit mechanisms govern the phasic mesolimbic dopamine response to nicotine PLoS Comput Biol. 2013;9:e1003183.

94. Zhang D, Gao M, Xu D, Shi WX, Gutkin BS, Steffensen SC, et al. Impact of prefrontal cortex in nicotine-induced excitation of ventral tegmental area dopamine neurons in anesthetized rats. J Neurosci. 2012;32:12366-75.

95. Tolu S, Eddine R, Marti F, David V, Graupner M, Pons S, et al. Co-activation of VTA DA and GABA neurons mediates nicotine reinforcement. Mol Psychiatry. 2013;18:382-93.

96. Exley R, Maubourguet N, David V, Eddine R, Evrard A, Pons S, et al. Distinct contributions of nicotinic acetylcholine receptor subunit alpha4 and subunit alpha6 to the reinforcing effects of nicotine. Proc Natl Acad Sci USA. 2011;108:7577-82

97. Berrettini W, Yuan X, Tozzi F, Song K, Francks C, Chilcoat H, et al. Alpha-5/alpha-3 nicotinic receptor subunit alleles increase risk for heavy smoking. Mol Psychiatry. 2008;13:368-73.

98. Lips EH, Gaborieau V, McKay JD, Chabrier A, Hung RJ, Boffetta P, et al. Association between a $15 q 25$ gene variant, smoking quantity and tobacco-related cancers among 17000 individuals. Int J Epidemiol. 2010;39:563-77.

99. Bierut LJ, Madden PA, Breslau N, Johnson EO, Hatsukami D, Pomerleau OF, et al. Novel genes identified in a high-density genome wide association study for nicotine dependence. Hum Mol Genet. 2007;16:24-35.

100. Saccone SF, Hinrichs AL, Saccone NL, Chase GA, Konvicka K, Madden PA, et al. Cholinergic nicotinic receptor genes implicated in a nicotine dependence association study targeting 348 candidate genes with 3713 SNPs. Hum Mol Genet. 2007;16:36-49.

101. Saccone NL, Saccone SF, Hinrichs AL, Stitzel JA, Duan W, Pergadia ML, et al. Multiple distinct risk loci for nicotine dependence identified by dense coverage of the complete family of nicotinic receptor subunit (CHRN) genes. Am J Med Genet B Neuropsychiatr Genet. 2009;150B:453-66.

102. Saccone NL, Wang JC, Breslau N, Johnson EO, Hatsukami D, Saccone SF, et al. The CHRNA5-CHRNA3-CHRNB4 nicotinic receptor subunit gene cluster affects risk for nicotine dependence in African-Americans and in European-Americans. Cancer Res. 2009;69:6848-56

103. Schlaepfer IR, Hoft NR, Collins AC, Corley RP, Hewitt JK, Hopfer CJ, et al. The CHRNA5/A3/B4 gene cluster variability as an important determinant of early alcohol and tobacco initiation in young adults. Biol Psychiatry. 2008;63: 1039-46.

104. De Biasi $M$, Salas R. Influence of neuronal nicotinic receptors over nicotine addiction and withdrawal. Exp Biol Med (Maywood). 2008;233:917-29.

105. Salas R, Sturm R, Boulter J, De Biasi M. Nicotinic receptors in the habenulointerpeduncular system are necessary for nicotine withdrawal in mice. J Neurosci. 2009;29:3014-8.

106. Cahill K, Lindson-Hawley N, Thomas KH, Fanshawe TR, Lancaster T. Nicotine receptor partial agonists for smoking cessation. Cochrane Database Syst Rev. 2016; (5): CD006103.

107. Wu J. Double target concept for smoking cessation. Acta Pharmacol Sin. 2010;31:1015-8.

108. Brunzell DH, Mclntosh JM, Papke RL. Diverse strategies targeting alpha7 homomeric and alpha6beta2* heteromeric nicotinic acetylcholine receptors for smoking cessation. Ann N Y Acad Sci. 2014;1327:27-45.

109. Marks MJ, O'Neill HC, Wynalda-Camozzi KM, Ortiz NC, Simmons EE, Short CA, et al. Chronic treatment with varenicline changes expression of four $\mathrm{nAChR}$ binding sites in mice. Neuropharmacology. 2015;99:142-55.

(i) Open Access This article is licensed under a Creative Commons Attribution 4.0 International License, which permits use, sharing, adaptation, distribution and reproduction in any medium or format, as long as you give appropriate credit to the original author(s) and the source, provide a link to the Creative Commons license, and indicate if changes were made. The images or other third party material in this article are included in the article's Creative Commons license, unless indicated otherwise in a credit line to the material. If material is not included in the article's Creative Commons license and your intended use is not permitted by statutory regulation or exceeds the permitted use, you will need to obtain permission directly from the copyright holder. To view a copy of this license, visit http://creativecommons. org/licenses/by/4.0/.

(c) CPS and SIMM 2019 